\title{
Palliative treatment of bone metastases: analysis of biological effects of MR guided Focused Ultrasound (MRgFUS) versus External Beam Radiation Therapy (EBRT). A randomized comparative trial using Functional Diffusion Maps as molecular activity indicator
}

\author{
Michele Anzidei", Alessandro Napoli, Giulia Brachetti, Maurizio Del Monte, Daniel De Olivera, Fabrizio Andrani, \\ Carola Palla, Luca Bertaccini, Daniela Musio, Vincenzo Tombolini, Carlo Catalano
}

From 2nd European Symposium on Focused Ultrasound Therapy

Rome, Italy. 10-11 October 2013

\begin{abstract}
Backgroud
New functional and metabolic imaging techniques may provide the ability to assess biological changes that act as indicators of therapy response [1,2]. Particularly, Diffusion-Weighted Imaging (DWI) can be used to monitor change in cellularity within the tumour over time, which is reflective of response to therapy [3-5]. Our study aims to investigate and compare the response to MR guided Focused Ultrasound (MRgFUS) and External Beam Radiation Therapy (EBRT) treatments of painful bone metastases by using DW Magnetic Resonance imaging (DW-MRI) with apparent diffusion coefficient (ADC). Furthermore, we analyzed the correlation between DWMRI and the Visual Analogue Scale (VAS).
\end{abstract}

\section{Materials and methods}

This prospective, double arm, randomized study with EBRT serving as control arm, received IRB approval. 36 consecutive patients (female:15 male:21 mean age:60.3) with painful bone metastases were enrolled. 18 patients underwent MRgFUS treatment, using ExAblate 2100 system (InSightec), and 18 patients underwent EBRT. Pain palliation was evaluated by visual analog scale (VAS), pain questionnaires and changes in the patients'

\footnotetext{
* Correspondence: michele.anzidei@gmail.com

Department of Radiological Oncological and Pathological Sciences,
}

"Sapienza"Unversity of Rome, Italy

\section{Results}

No treatment-related adverse events were recorded for both arms. Statistically significant difference between baseline and follow-up VAS values and medication intake for both MRgFUS and EBRT patients $(\mathrm{p}<0.05)$ was noted. DWI showed substantial increase in mean ADC values after treatment for both MRgFUS (pre:1080,6 $\pm 269 \mathrm{~mm}^{2} / \mathrm{s}$; post: $1577,5 \pm 311,6$ ) and EBRT (pre:1313,3 $\pm 424,3 \mathrm{~mm}^{2} / \mathrm{s}$; post:1777,9 $\pm 386,3$ ); there were no significant statistical differences in ADC shift following between MRgFUS and ERBT ( $p>0.5$ ). Progressive decrease in VAS values positively correlated to an increase in mean ADC values ( $>00.01)$ for both treatment modalities (Tables 1,2$)$.

\section{Conclusions}

DW-MRI with ADC is a viable option for assessing tumor response to MRgFUS therapy for bone metastases. The increase in mean ADC values of ablated bone 
Table 1

\begin{tabular}{lllll}
\hline MRgFUS & baseline & Follow-up 1 month & Follow-up 2 months & Follow-up 3 months \\
\hline ADC & $1080.6 \pm 269 \mathrm{~mm}^{2} / \mathrm{s}$ & $1347.2 \pm 294 \mathrm{~mm}^{2} / \mathrm{s}$ & $1428.7 \pm 306.7 \mathrm{~mm}^{2} / \mathrm{s}$ & $1577.5 \pm 311.6 \mathrm{~mm}^{2} / \mathrm{s}$ \\
\hline VAS & $7.09 \pm 1.8($ range 4-10) & $2.65 \pm 1.36($ range 0-5) & $1.04 \pm 1.91($ range 0-6) & $1.09 \pm 1.99($ range 0-6) \\
\hline
\end{tabular}

\section{Table 2}

\begin{tabular}{lllll}
\hline EBRT & baseline & Follow-up 1 month & Follow-up 2 months & Follow-up 3 months \\
\hline ADC & $1313.3 \pm 424.3 \mathrm{~mm}^{2} / \mathrm{s}$ & $1463 \pm 361.7 \mathrm{~mm}^{2} / \mathrm{s}$ & $1611 \pm 373.2 \mathrm{~mm}^{2} / \mathrm{s}$ & $1777.9 \pm 386.3 \mathrm{~mm}^{2} / \mathrm{s}$ \\
\hline VAS & $6.12 \pm 1.1($ range $5-10)$ & $3.51 \pm 1.54($ range $0-6)$ & $1.32 \pm 1.48($ range $0-4)$ & $1.02 \pm 1.36($ range $0-4)$ \\
\hline
\end{tabular}

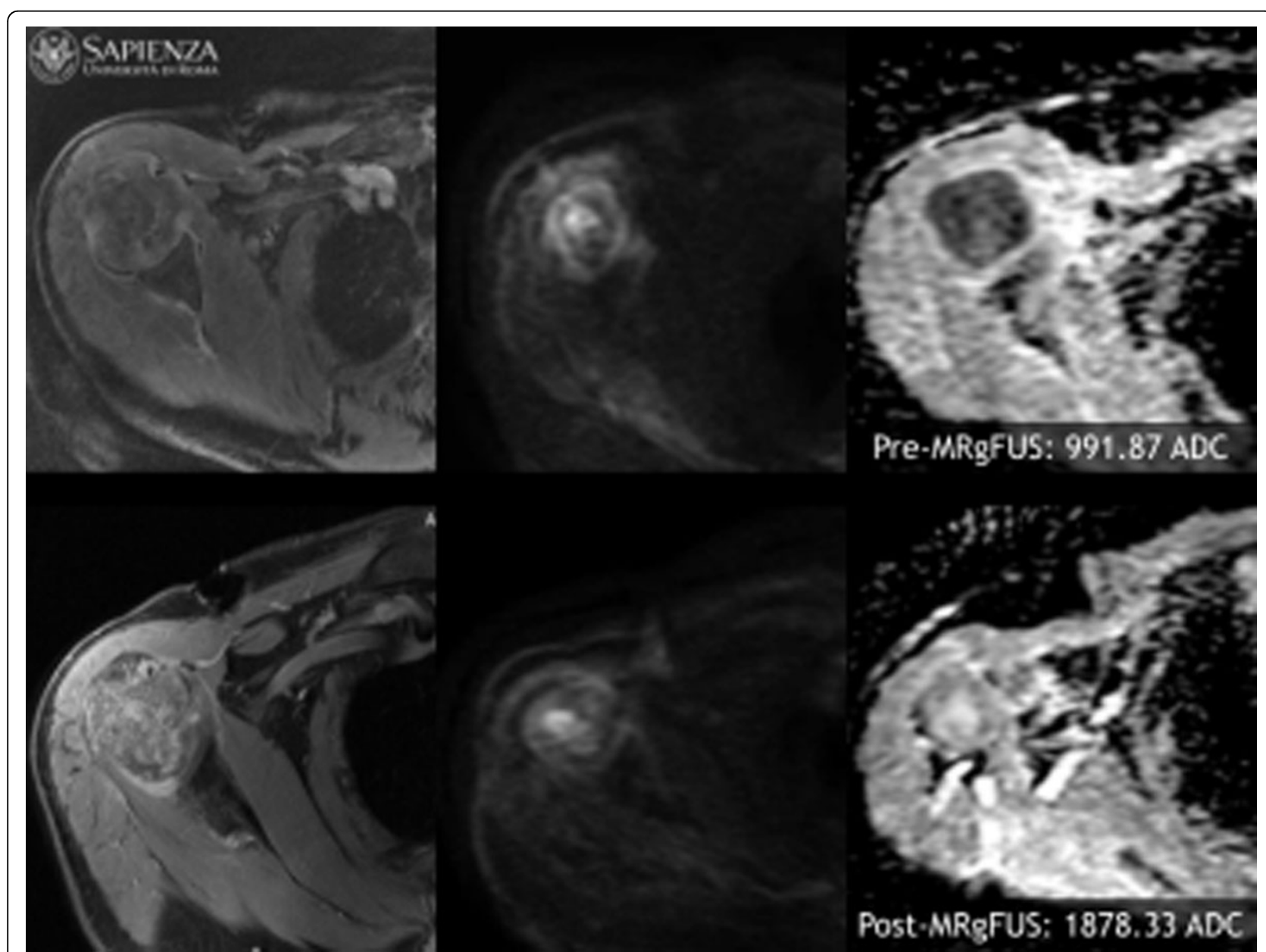

Figure 167 years old patient with lung cancer. MR images acquired before and after MR guided ultrasound treatment shows increase ADC value at 3 months follow-up $\left(1878.33 \mathrm{~mm}^{2} / \mathrm{s}\right)$ compared to baseline $\left(991.87 \mathrm{~mm}^{2} / \mathrm{s}\right)$. Also at the end of follow-up we observed absence of pain (VAS baseline: 7; VAS 3 months: 0).

metastases could reflect pathophysiologic alterations that occur after ablative therapy [6]. It is therefore possible that ADC variations could effectively describe and express effects on tumor mass control induced by focused ultrasound ablation. MRgFUS is a promising noninvasive treatment modality for successful palliation of bone metastasis [7] and has potential for tumor control (Figures 1,2) [8] as compared to ERBT. MRgFUS 


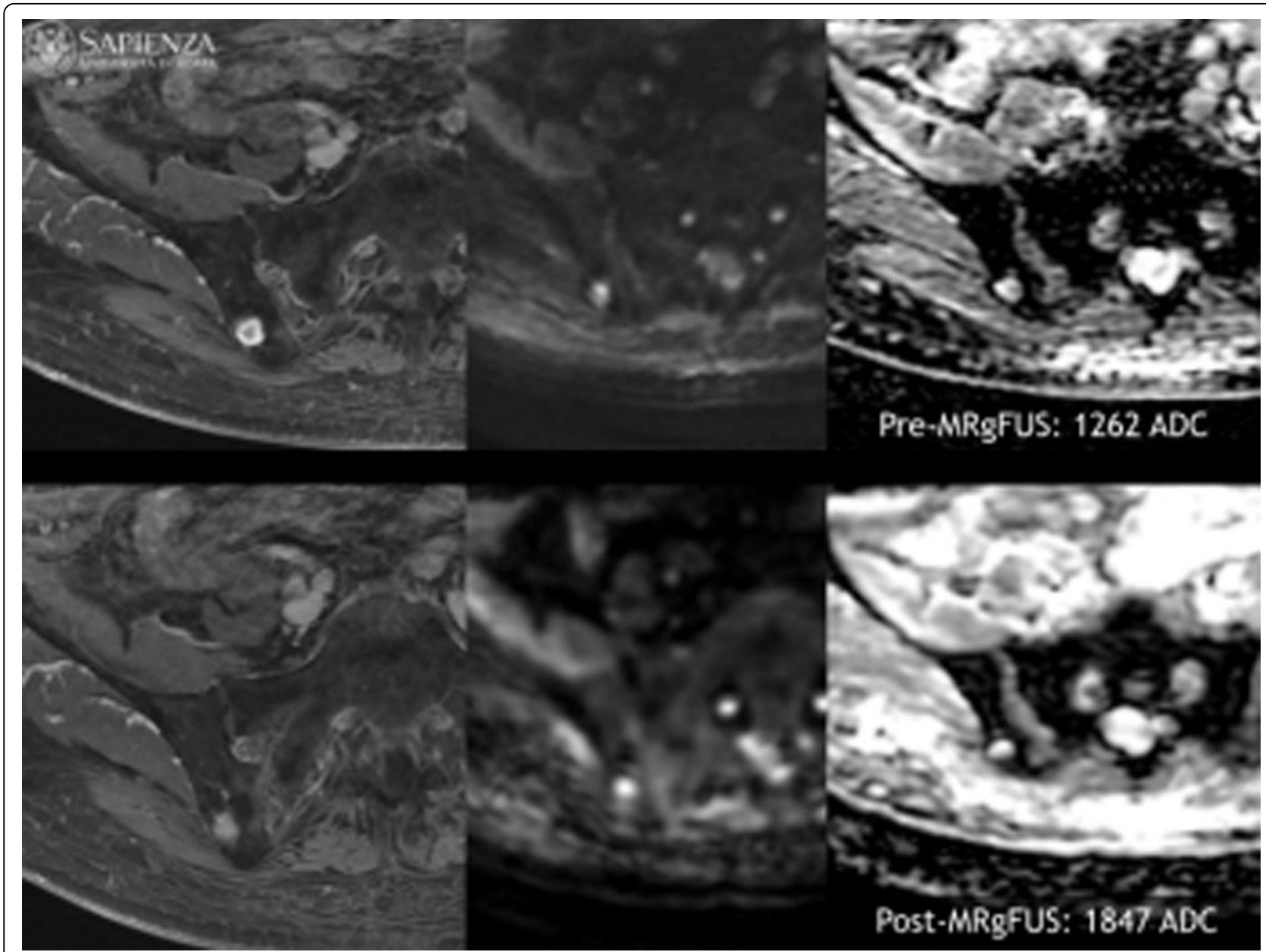

Figure 270 years old patient with renal cell carcinoma. Same as figure 1, it has been verified an increase ADC value after MR guided ultrasound treatment (ADC baseline: $1262 \mathrm{~mm}^{2} / \mathrm{s}$. ADC 3 months: $1847 \mathrm{~mm}^{2} / \mathrm{s}$ ). At 3 months follow-up VAS value 4 (VAS baseline 8).

determines bone metastasis cell damage similarly to EBRT as demonstrated by linear ADC modification.

Published: 10 December 2014

\section{References}

1. Harry VN, et al: Use of new imaging techniques to predict tumour response to therapy. Lancet Oncol 2010, 11:92-102.

2. Vassiliou V, et al: Bone metastases: assessment of therapeutic response through radiological and nuclear medicine imaging modalities. Clin Oncol (R Coll Radiol) 2011, 23(9):632-45.

3. Charles-Edwards EM, et al: Diffusion-weighted magnetic resonance imaging and its application to cancer. Cancer Imaging 2006, 6:135-143.

4. Reischauer $C$, et al: Bone metastases from prostate cancer: assessing treatment response by using diffusion-weighted imaging and functional diffusion maps. Initial Observations. Radiology 2010, 257:2.

5. Mardor $Y$, et al: Early detection of response to radiation therapy in patients with brain malignancies using conventional and high b-value diffusion-weighted magnetic resonance imaging. J Clin Oncol 2003, 21(6):1094-100.

6. Smith NB, et al: Thermal effects of focused ultrasound energy on bone tissue. Ultrasound Med Biol 2001, 27(10):1427-33.

7. Napoli A, Anzidei M, Marincola BC, Brachetti G, Noce V, Boni F, Bertaccini L, Passariello R, Catalano C: MR Imaging-guided Focused Ultrasound for
Treatment of Bone Metastasis. Radiographics 2013, 33(6):1555-68, doi: 10.1148/rg.336125162.

8. Napoli A, Anzidei M, Marincola BC, Brachetti G, Ciolina F, Cartocci G, Marsecano C, Zaccagna F, Marchetti L, Cortesi E, Catalano C: Primary pain palliation and local tumor control in bone metastases treated with magnetic resonance-guided focused ultrasound. Invest Radiol 2013, 48(6):351-8, doi: 10.1097/RLI.0b013e318285bbab.

doi:10.1186/2050-5736-2-S1-A17

Cite this article as: Anzidei et al:: Palliative treatment of bone metastases: analysis of biological effects of MR guided Focused Ultrasound (MRgFUS) versus External Beam Radiation Therapy (EBRT). A randomized comparative trial using Functional Diffusion Maps as molecular activity indicator. Journal of Therapeutic Ultrasound 2014 2(Suppl 1):A17. 